\title{
INVESTIGATION OF AN ALUMINOTHERMIC SILICON SEPARATION FROM A CORUNDUM MATRIX
}

\author{
V. M. Shevko ${ }^{1, *}$, A. D. Badikova ${ }^{1}$, D. D. Amanov ${ }^{1}$, G. E. Karataeva ${ }^{1}$ \\ and B. A. Lavrov ${ }^{2}$ \\ ${ }^{1}$ South Kazakhstan State University named after M. Auezov, Kazakhstan,160012, \\ Shymkent, Tauke Khan Avenue, 5 \\ ${ }^{2}$ St. Petersburg State Technological Institute (Technical University), \\ Russia, 190013, St. Petersburg, Moscow Avenue, 26 \\ *E-mail: sunstroke_91@mail.ru
}

\begin{abstract}
The presented paper contains the research results of extraction of the reduced silicon from the corundum matrix by means of different methods. The research has been performed with use of several methods: separation in a heavy suspension, sedimentation in high-viscous mediums and electrostatic separation. The results obtained at the studying of separation of the matrix (corundum) and the silicon produced from quartz glass and aluminium powder allowed to draw following conclusions: separation in an alcohol-bromoform medium allows to take no more than $16 \%$ of silicon; in the process the silicon concentration in the product makes $40-42 \%$; at use of a water-glycerine mixture the silicon content in the product makes $39-49 \%$, and the extraction degree of $\mathrm{Si}$ in it is no more than $32 \%$; electrostatic separation allows to extract into the product $83-89 \%$ of $\mathrm{Si}$; in this case the product contains $88-92 \%$ of silicon; application of iodine transport (the "inverted crucible" technique) allows to produce high-pure (99\%) silicon at the actual extraction of $72,5 \%$ and predicted one $-88,7 \%$; for obtaining purer silicon $(99,9999 \%$ of $\mathrm{Si}$ ) we recommend to use vacuum purification.
\end{abstract}

Keywords: silicon, corundum matrix, heavy suspension, sedimentation, electrostatic separation.

@ RASĀYAN. All rights reserved

\section{INTRODUCTION}

In world practice, there are known various methods of producing silicon of high purity ${ }^{1-6}$. For example, obtaining silicon by purification of metallurgical silicon to the necessary purity, obtaining silicon from high purity quartz through its recovery and subsequent post-treatment methods using trichlorosilane and monosilane, with subsequent recovery or pyrolysis of silicon-containing intermediate compounds and obtaining polycrystalline silicon.

As we have noted in previous works, at the aluminothermic production of silicon from quartz glass and aluminium powder the silicon reduction degree in accordance with the reaction:

$3 \mathrm{SiO}_{2}+4 \mathrm{Al}=3 \mathrm{Si}+2 \mathrm{Al}_{2} \mathrm{O}_{3}$

at $1260^{\circ} \mathrm{C}$ within 6 minutes makes $91 \%$, and at $1300^{\circ} \mathrm{C}$ within the same time practically all the silicon is reduced $^{7-8}$. The microscope studying has shown, that a great bulk of the reduced silicon $(\approx 60-65 \%)$ is in pores of a corundum matrix as particles with sizes of $0,01-0,5 \mathrm{~mm}$ and thin films rigidly bound with the matrix surface. For this reason, extraction of the reduced silicon from the matrix is sufficiently difficult. The presented paper contains the research results of extraction of the reduced silicon from the corundum matrix by means of different methods.

\section{EXPERIMENTAL}

The research has been performed with use of several methods: separation in a heavy suspension, sedimentation in high-viscous mediums and electrostatic separation. The separation in a heavy suspension has been realized with application of bromoform with density of $2,89 \mathrm{~g} / \mathrm{cm}^{3}$.

Rasayan J. Chem., 11(3), 1050-1057(2018)

http://dx.doi.org/10.31788/RJC.2018.1132038

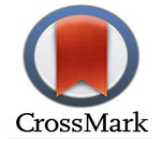


The method is based on a difference between densities of $\mathrm{Si}\left(2,33 \mathrm{~g} / \mathrm{cm}^{3}\right)$ and $\mathrm{Al}_{2} \mathrm{O}_{3}\left(3,97 \mathrm{~g} / \mathrm{cm}^{3}\right)$. Before the separation, a corundum matrix and silicon had been ground to a fraction of $0,1-0,16 \mathrm{~mm}$. A sample of the ground material $(2 \mathrm{~g})$ was placed in a graduated glass. Then $6 \mathrm{ml}$ of the bromoform were added to the glass. After the first sedimentation of a heavy fraction (corundum) its volume was measured. Then the bromoform in the glass was diluted with a solvent (ethyl alcohol). At a performance of the research, we have used several alcohol-bromoform mixtures, which densities is represented in Table-1.

Table-1: Density of alcohol-bromoform mixtures.

\begin{tabular}{l|l|l|l|l|l|l|l|l}
\hline $\mathrm{V}_{\mathrm{bf}}, \%^{*}$ & 100 & 88 & 86 & 75 & 60 & 50 & 40 & 25 \\
\hline $\mathrm{D}, \mathrm{g} / \mathrm{cm}^{3^{\circ}}$ & 2,89 & 2,55 & 2,50 & 2,43 & 2,16 & 1,86 & 1,69 & 1,32 \\
\hline
\end{tabular}

Note: ${ }^{*}-$ a volume fraction of bromoform; ${ }^{\circ}-$ the density of a liquid.

The bromoform, the sample and the alcohol were carefully mixed by a glass stick. After precipitation of a deposit, its volume was measured. The sedimentation and dilution stages were repeated from 3 to 5 times for obtaining of fractions with various densities within the limits of the density of the liquid, which was applied for the mixture separation.

For the implementation of the sedimentation analysis, a sample of the investigated powder with a fraction of 125 microns and weight of $2 \mathrm{~g}$ is placed in preliminary prepared measured cylinders and filled with a dispersive medium (water and glycerine), which total volume is $6 \mathrm{ml}$. Then the prepared suspension is carefully mixed. This analysis is realized by means of so-called a method of continuous determination of a sedimentation deposit. On the basis of experimental data, a curve of a phenomenological description of particles' precipitation kinetics from time is constructed. A light fraction after the separation is filtered. A cinder on a filter after drying is analyzed by roentgen-phase techniques.

Electrostatic separation has been performed on a device ELKOR-1 (Russia). The separator is intended for separation of mixtures of loose materials with a grain of $0,1-5 \mathrm{~mm}$ differing by electric properties.

\section{RESULTS AND DISCUSSION}

The experiments with the use of bromoform allowed determining the optimum ratios of the alcohol and bromoform at which the greatest extraction degree of silicon from the corundum has been achieved. The silicon extraction degree has been determined by a roentgen-phase analysis of the obtained mixture at the use of a bromoform-alcohol mixture with a density of $2,5 \mathrm{~g} / \mathrm{cm}^{3}$ and $2,55 \mathrm{~g} / \mathrm{cm}^{3}$. Results of the roentgenphase analysis of the top phase with the use of a bromoform-alcohol mixture with a density of $2,55 \mathrm{~g} / \mathrm{cm}^{3}$ are represented in Fig.-1.

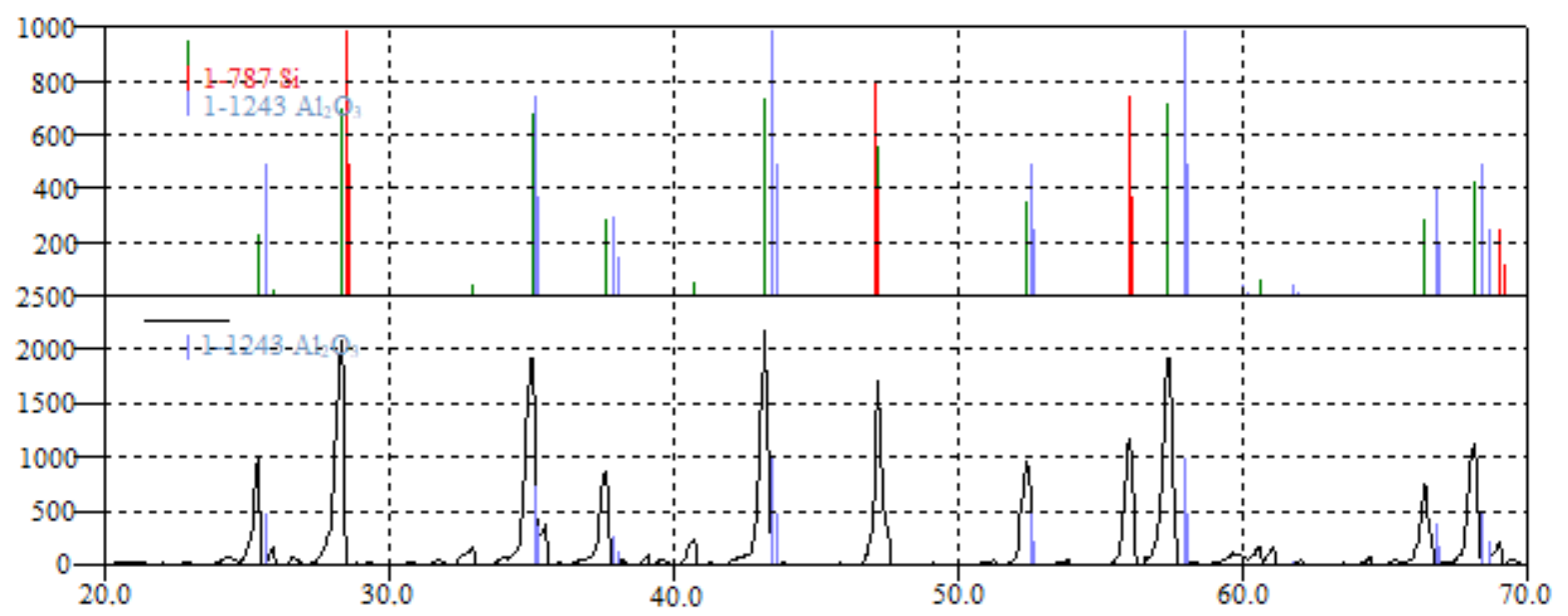

Fig.-1: Roentgen-phase analysis of a silicon-corundum mixture at the use of a bromoform-alcohol mixture with a density of $2,55 \mathrm{~g} / \mathrm{cm}^{3}$.

The silicon extraction degree into a dry deposit - a concentrate - was no more than $16 \%$. As a result of the eightfold separation of this deposit, we could obtain pure silicon (purity of 99,3\%). At the work with 
bromoform, the yellow coloration of liquid layers over the charge has been noticed. This phenomenon is connected with the decomposition of bromoform under light and formation of hydrogen bromide and molecular bromine ${ }^{9-10}$ :

$\mathrm{CHBr}_{3} \rightarrow \mathrm{HBr}+\mathrm{Br}_{2}$

Silicon and corundum can react with $\mathrm{HBr}$ and $\mathrm{Br}_{2}$ giving different by-products $\left(\mathrm{SiBr}_{4}, \mathrm{AlBr}_{3}, \mathrm{HBr}\right.$, etc.), which complicate the $\mathrm{Si}-\mathrm{Al}_{2} \mathrm{O}_{3}$ separation process.

Low indicators of the separation in a bromoform medium are also connected with the fact that a basic part of the obtained silicon represents the fine-dispersed particles and films closely bound with the matrix. Their removal demands very thin grinding. However, in this case, a difference between the silicon and corundum densities is imperceptible, that leads to a stop of the separation process. Therefore, the separation of the matrix from the silicon with use of a bromoform-alcohol mixture is not an optimum variant. For the $\mathrm{Si}_{-} \mathrm{Al}_{2} \mathrm{O}_{3}$ separation from a fine-dispersed material, it is suggested to apply a viscous medium, for example, glycerine.

At the implementation of experiments in a water-glycerine mixture, we have determined a ratio of the deposit volume $(\mathrm{V})$ to the suspension total amount $\left(\mathrm{V}_{\mathrm{o}}\right)$. On the basis of these data dependences of $\mathrm{V} / \mathrm{V}_{\mathrm{o}}=$ [gamma] on time and viscosity of a dispersive medium have been constructed (Fig.-2).
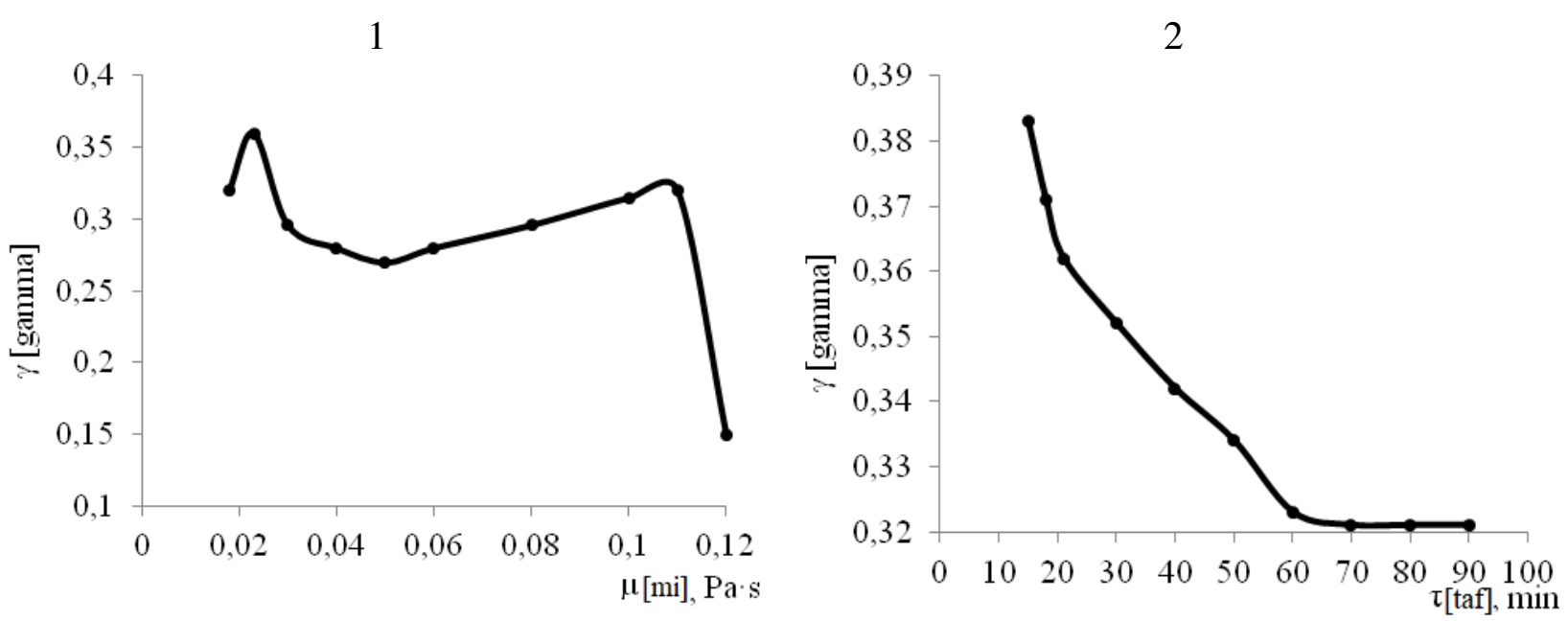

$$
1-[\mathrm{taf}]=60 \mathrm{~min}, 2-[\mathrm{mi}]=0,025 \mathrm{~Pa} \cdot \mathrm{s}
$$

Fig.-2: Effect of a dispersive medium's viscosity and sedimentation time of solid particles on [gamma].

By reason of a complex character of viscosity influence on [gamma] in intervals of $0,018-0,031 \mathrm{~Pa} \cdot \mathrm{s}$ and 0,1-0,12 $\mathrm{Pa} \cdot \mathrm{s}$ we have applied a rotatable second-order method of planning an experiment ${ }^{11-12}$. The experiments, connected with studying the joint influence of viscosity and time on [gamma], have been carried out for two above-stated viscosity intervals. The planning matrix and obtained results are represented in Tables- 2 and 3.

The equations 1, 2 have been applied for construction of three-dimensional response surfaces and their horizontal sections (Fig. 3). Figure 4 is a photo of the cylinders, which have been used for the separation of corundum from silicon at different densities of water-glycerine mixtures.

At a viscosity of $0,12 \mathrm{~Pa} \cdot \mathrm{s}$ the corundum deposit becomes denser. At the same time in the volume over the dense $\mathrm{Al}_{2} \mathrm{O}_{3}$ deposit, there is the formation of a suspension of easier silicon (Fig. 4). The formation conditions of the dense $\mathrm{Al}_{2} \mathrm{O}_{3}$ deposit (at [gamma] $\leq 0,2$ ) and the silicon suspension can be determined from Fig. 3, according to which $\mu$ should be within 0,117-0,12 Pa.s and sedimentation time from 10 to 60 minutes, and for [gamma] from 0,15 to 0,152 the suspension viscosity makes $0,119-0,12 \mathrm{MPa}$ and sedimentation time 45-60 minutes. 
RASĀYAN J. Chem.

Vol. 11 | No. 3 |1050 - 1057 | July - September | 2018

For effective extraction of silicon from this suspension we have carried out the experiment, which combines sedimentation and flotation processes. For this purpose, a bubbler, controlling a quantity of fed bubbles, is placed in a quartz vessel. The bubbles form a pulp-air mixture, lift the powder from the bottom and, ipso facto, promote fuller separation of heavy particles. Figures 5 and 6 show the formation of airsilicon bubbles on a surface of the water-glycerine mixture with the subsequent extraction of silicon. Silicon content in a dry powder of the top phase makes $39-49 \%$. However, the silicon extraction degree into the top phase is only $24-32 \%$.

Table-2: A matrix of planning an experiment and results of the effect of the separation time and the system density in the interval of $0,018-0,032 \mathrm{~Pa} \cdot \mathrm{s}$ on $\mathrm{V} / \mathrm{V}_{0}$

\begin{tabular}{c|c|c|c|c}
\hline \multicolumn{4}{c|}{ Variables } & \multirow{2}{*}{$\begin{array}{c}\mathrm{V}_{0} / \mathrm{V}_{\mathrm{c}}= \\
\text { [gamma] }\end{array}$} \\
\cline { 1 - 3 } $\mathrm{x}_{1}$ & $\mathrm{x}_{2}$ & $\begin{array}{c}\text { Node kind } \\
\mathrm{Pa} \cdot \mathrm{s}\end{array}$ & $\begin{array}{c}\text { [taf], } \\
\text { min }\end{array}$ & \\
\hline+ & + & 0,03 & 53 & 0,296 \\
\hline- & + & 0,02 & 53 & 0,323 \\
\hline+ & - & 0,03 & 17 & 0,330 \\
\hline- & - & 0,02 & 17 & 0,341 \\
\hline 1,41 & 0 & 0,032 & 35 & 0,295 \\
\hline$-1,41$ & 0 & 0,018 & 35 & 0,319 \\
\hline 0 & 1,41 & 0,025 & 60 & 0,321 \\
\hline 0 & $-1,41$ & 0,025 & 10 & 0,376 \\
\hline 0 & 0 & 0,025 & 35 & 0,363 \\
\hline 0 & 0 & 0,025 & 35 & 0,354 \\
\hline 0 & 0 & 0,025 & 35 & 0,332 \\
\hline 0 & 0 & 0,025 & 35 & 0,366 \\
\hline 0 & 0 & 0,025 & 35 & 0,349 \\
\hline & & & & \\
\hline
\end{tabular}

Table-3: A matrix of planning an experiment and results of the effect of the separation time and the system density in the interval of $0,1-0,12 \mathrm{~Pa} \cdot \mathrm{s}$ on $\mathrm{V} / \mathrm{V}_{0}$.

\begin{tabular}{|c|c|c|c|c|}
\hline \multicolumn{4}{|c|}{ Variables } & \multirow{3}{*}{$\begin{array}{c}\mathrm{V}_{0} / \mathrm{V}_{\mathrm{c}}= \\
\text { [gamma] }\end{array}$} \\
\hline \multicolumn{2}{|c|}{ Code kind } & \multicolumn{2}{|c|}{ Natural kind } & \\
\hline $\mathrm{X}_{1}$ & $\mathrm{X}_{2}$ & $\begin{array}{l}{[\mathrm{mi}]} \\
\mathrm{Pa} \cdot \mathrm{s}\end{array}$ & $\begin{array}{c}\text { [taf] } \\
\text { min }\end{array}$ & \\
\hline+ & + & 0,117 & 53 & 0,296 \\
\hline- & + & 0,103 & 53 & 0,323 \\
\hline+ & - & 0,117 & 17 & 0,330 \\
\hline- & - & 0,103 & 17 & 0,341 \\
\hline 1,41 & 0 & 0,12 & 35 & 0,295 \\
\hline$-1,41$ & 0 & 0,10 & 35 & 0,319 \\
\hline 0 & 1,41 & 0,11 & 60 & 0,321 \\
\hline 0 & $-1,41$ & 0,11 & 10 & 0,376 \\
\hline 0 & 0 & 0,11 & 35 & 0,363 \\
\hline 0 & 0 & 0,11 & 35 & 0,354 \\
\hline 0 & 0 & 0,11 & 35 & 0,332 \\
\hline 0 & 0 & 0,11 & 35 & 0,366 \\
\hline 0 & 0 & 0,11 & 35 & 0,349 \\
\hline
\end{tabular}

On the basis of the data (Table-2 and 3) following adequate regression equations have been obtained: $\gamma(0,018-0,032)=0,11+21,159 \times \mu-1,705 \times 10^{-5} \times \tau-432,857 \times \mu^{2}-7,36 \times 10^{-7} \times \tau^{2}-2,285 \times \mu \times \tau$ $\gamma(0,1-0,12)=5,166+105,209 \times \mu-1,168 \times 10^{-3} \times \tau-505,2 \times \mu^{2}-9,62 \times 10^{-7} \times \tau^{2}+0,012 \times \mu \times \tau$

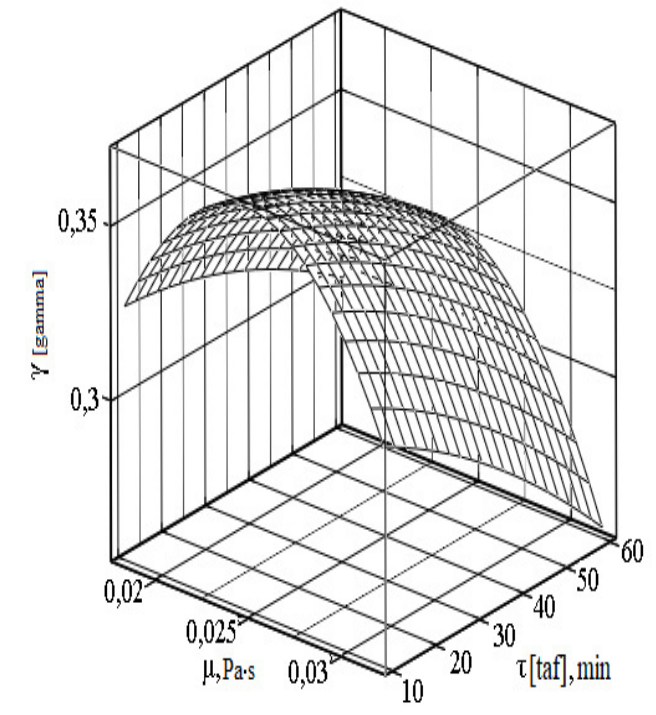

I

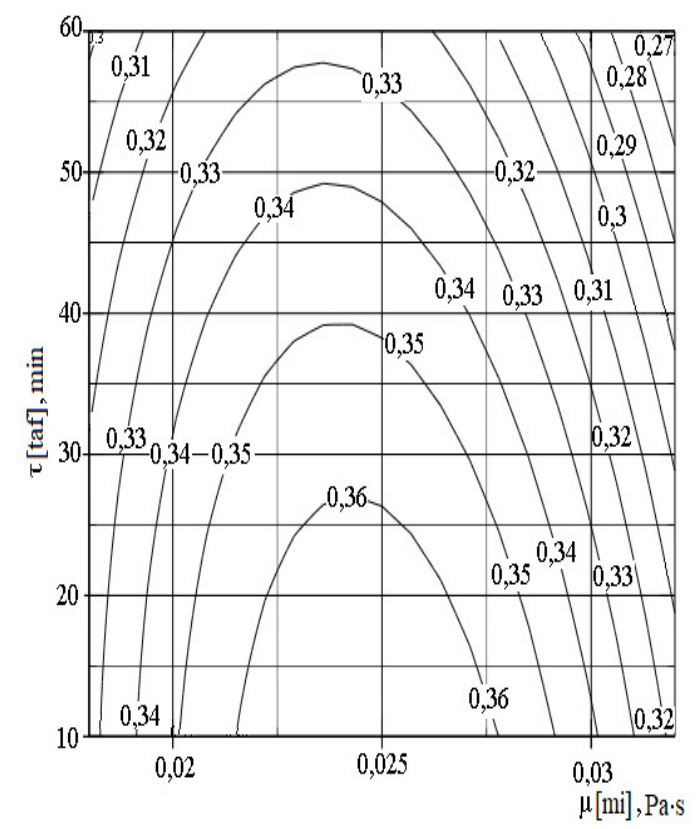


RASĀYAN J. Chem.

Vol. 11 | No. 3 |1050 - 1057 | July - September | 2018

II
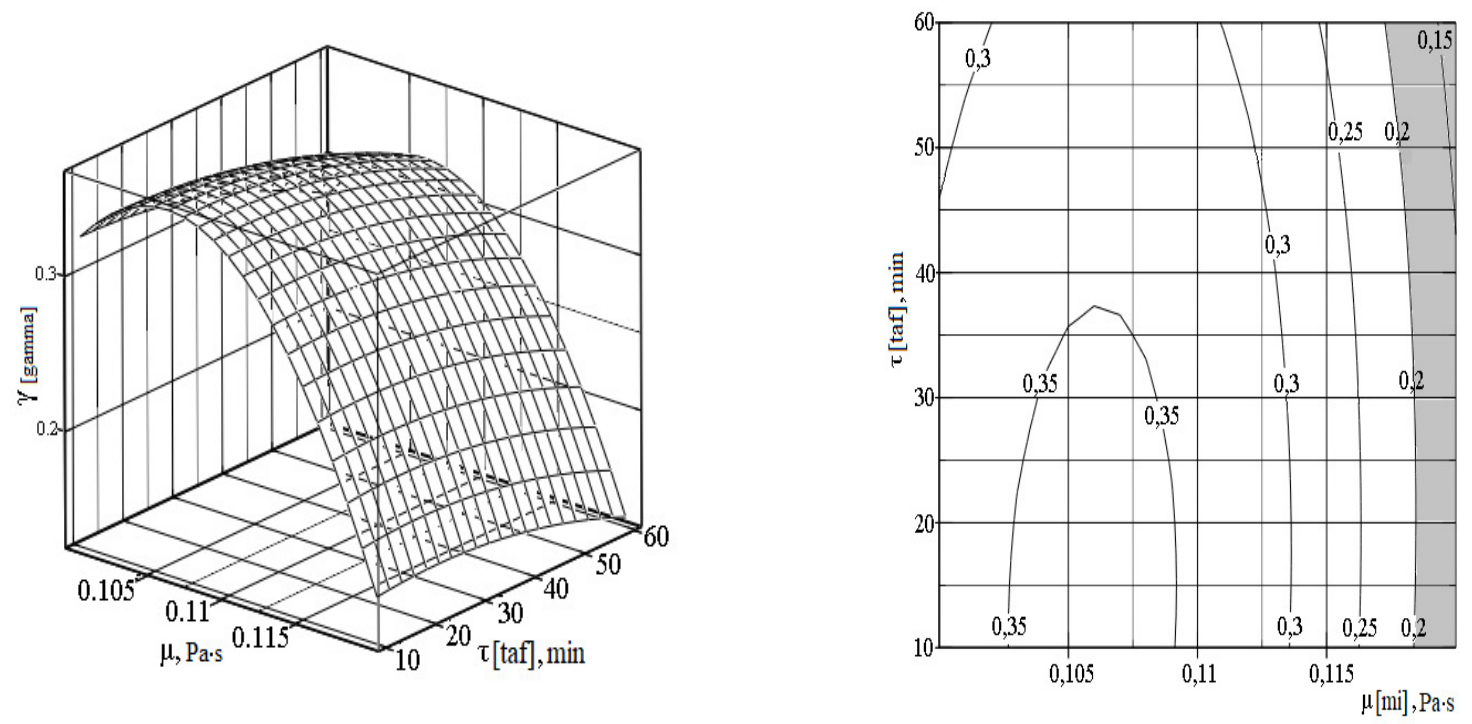

$\mathrm{I}-[\mathrm{mi}]=0,018-0,03 \mathrm{~Pa} \cdot \mathrm{s} ; \mathrm{II}-[\mathrm{mi}]=0,1-0,12 \mathrm{~Pa} \cdot \mathrm{s} ;$ the numerals on the lines $-\mathrm{V} / \mathrm{Vo}=[\mathrm{gamma}]$

Fig.-3: Time and viscosity effect on a Vo/Vc ratio.
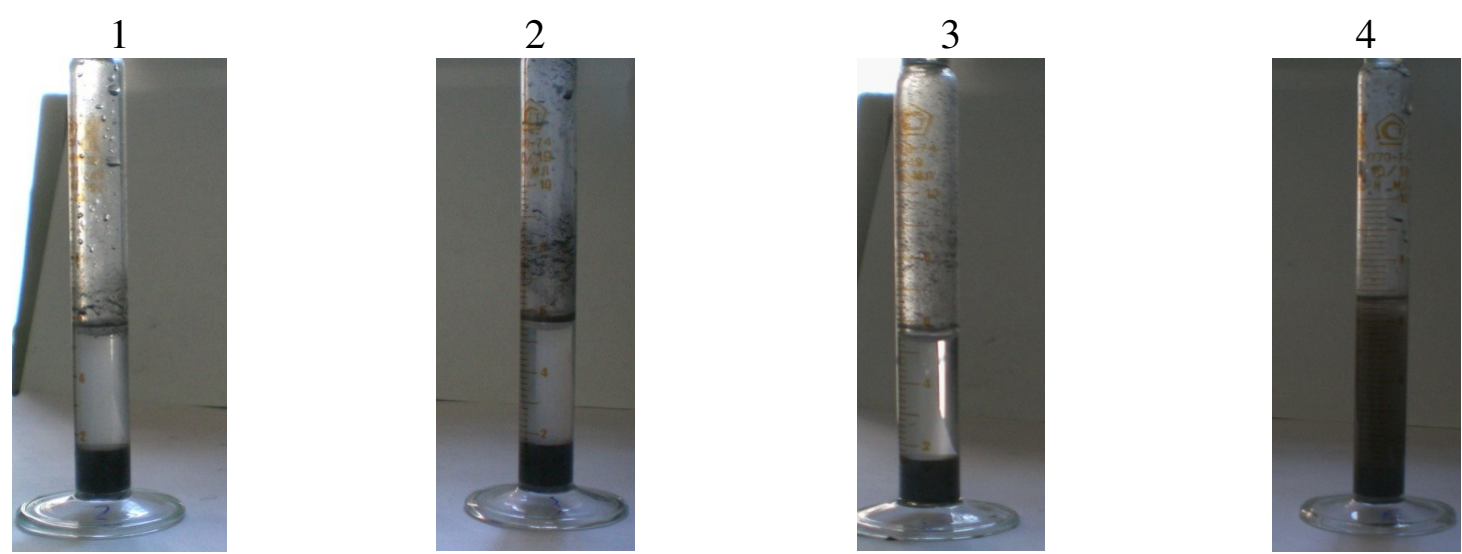

Fig.-4: Matrix-silicon separation pictures for viscosity of a water-glycerine mixture of $0,018 \mathrm{~Pa} \cdot \mathrm{s}(1), 0,025 \mathrm{~Pa} \cdot \mathrm{s}(2)$, $0,11 \mathrm{~Pa} \cdot \mathrm{s}(3)$ and $0,12 \mathrm{~Pa} \cdot \mathrm{s}(4)$.

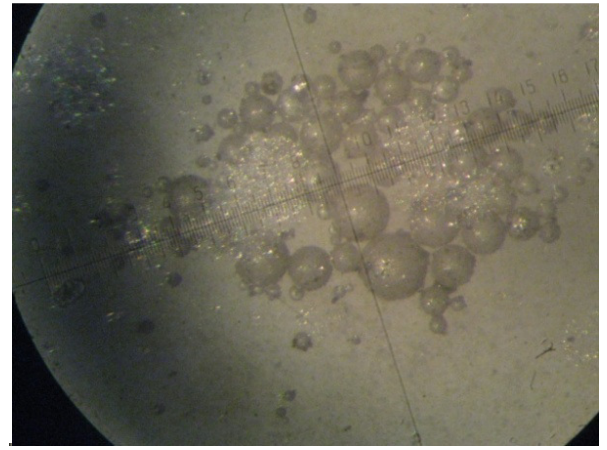

Fig.-5: Formation of air-silicon bubbles.

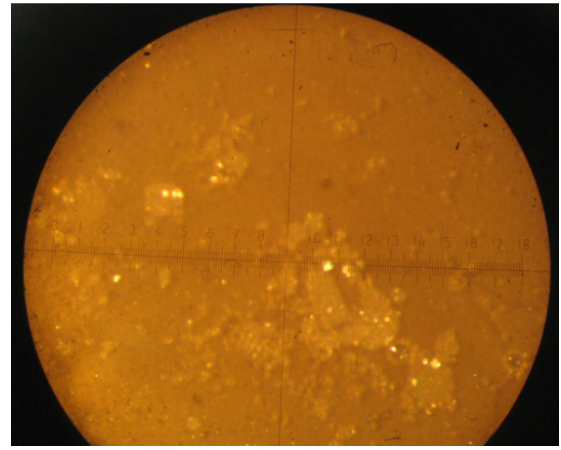

Fig.-6: Distribution of silicon on the liquid surface.

The analysis of the top phase of the foam formed on a surface of the water-glycerine mixture is represented in Fig.-7. 
For reduction of a quantity of the fine-crystalline silicon particles closely bound with the simultaneously formed corundum matrix, it is necessary to organize such the process, when the silicon and the corundum will be formed non-simultaneously. With this end in view, we have carried out the experiments in accordance with the technique of inverted crucible suggested by Digonsky ${ }^{13}$ for studying of reactions with use of gaseous hydrogen. The problem consists in using of gas transport during the reduction process and obtaining silicon in one stage with its simultaneous purification. Realization of the reduction reaction in a closed crucible allows organizing counter-current flows of iodine and silicon iodides ${ }^{7}$.

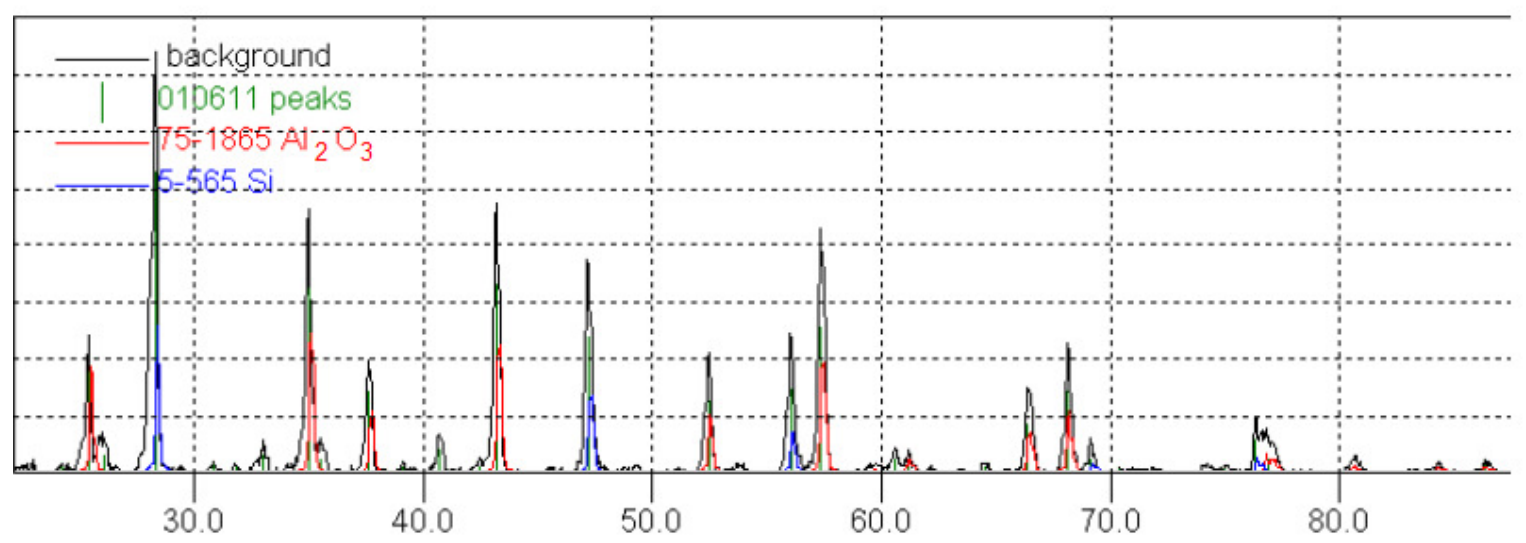

Fig.-7: Analysis of separation of the powders in a water-glycerine medium.

In this case the silicon sedimentation in the top part occurs not at the expense of reduction but owing to the reaction: $\mathrm{SiI}_{4} \rightarrow \mathrm{Si}+2 \mathrm{I}_{2}$. Therefore, such the silicon is not fixed rigidly in a corundum matrix. The given experimental technique is described in $^{14}$. In addition, we have performed experiments with a sample of a pelleted charge with the weight of $1000 \mathrm{~g}$ ( $625 \mathrm{~g}$ of quartz glass and $375 \mathrm{~g}$ of an aluminium powder). The charge pellets after roasting have been ground to a size of $1 \mathrm{~mm}$ and loaded in a crucible with the addition of $3 \mathrm{~g}$ of iodine. Then the charge is heated in a non-isothermal regime to a temperature of $1850 \mathrm{~K}$ in the top part within 10 minutes. Microscopic studying has shown that the most part of the silicon has no rigid fastening with corundum and represent the fine (10-20 microns) particles and globules located in pores of the sintered material. A technology of this process and material flows are represented in Figure 8 from which follows, that $625 \mathrm{~g}$ of quartz glass $(290,21 \mathrm{~g}$ of $\mathrm{Si})$ give $212,5 \mathrm{~g}$ of enriched silicon $(210,38 \mathrm{~g}$ of $\mathrm{Si}$ ).

Thus, the silicon extraction degree into the product is $72,5 \%$. The silicon losses $(27,5 \%)$ are connected with the laboratory equipment imperfection, in particular, $16,2 \%$ of $\mathrm{Si}(47,5 \mathrm{~g})$ have been lost with a dustlike phase at the mechanical size grading failing necessary dust removal equipment. Therefore, the actual output of the end product (purity of $99 \%$ ) makes $88,7 \%$. A silicon with purity of $99,9999 \%(6 \mathrm{~N})$ can be obtained by vacuum cleaning ${ }^{15-19}$. With a purpose of electrostatic separation of the matrix from the reduced silicon the briquettes after the thermal processing have been ground to fraction $<500$ microns. After processing in a device ELKOR-1 it has been established, that an electroconductive fraction makes $29-30 \%$, and a non-electroconductive fraction $-70-71 \%$. The microscopic analysis has shown that the electroconductive fraction is mainly composed of silicon globules and scales. Some scales are fixed with the corundum. The spectral analysis of the fraction has shown that silicon content is $88-92 \%$ and aluminium oxide content is $8-12 \%$. The experiments have shown that the silicon extraction degree from the matrix makes $83-89 \%$ that exceeds industrial indicators of existing technologies in several times.

\section{CONCLUSION}

The results obtained at the studying of separation of the matrix (corundum) and the silicon produced from quartz glass and aluminium powder allowed to draw the following conclusions:

- separation in an alcohol-bromoform medium allows to take no more than $16 \%$ of silicon; in the process, the silicon concentration in the product makes $40-42 \%$; 
- at the use of a water-glycerine mixture, the silicon content in the product makes $39-49 \%$, and the extraction degree of $\mathrm{Si}$ in it is no more than $32 \%$.

- electrostatic separation allows to extract into the product $83-89 \%$ of $\mathrm{Si}$; in this case, the product contains $88-92 \%$ of silicon;

- application of iodine transport (the "inverted crucible" technique) allows to produce high-pure (99\%) silicon at the actual extraction of $72,5 \%$ and predicted one $-88,7 \%$; for obtaining purer silicon $(99,9999 \%$ of $\mathrm{Si})$ we recommend to use vacuum purification.

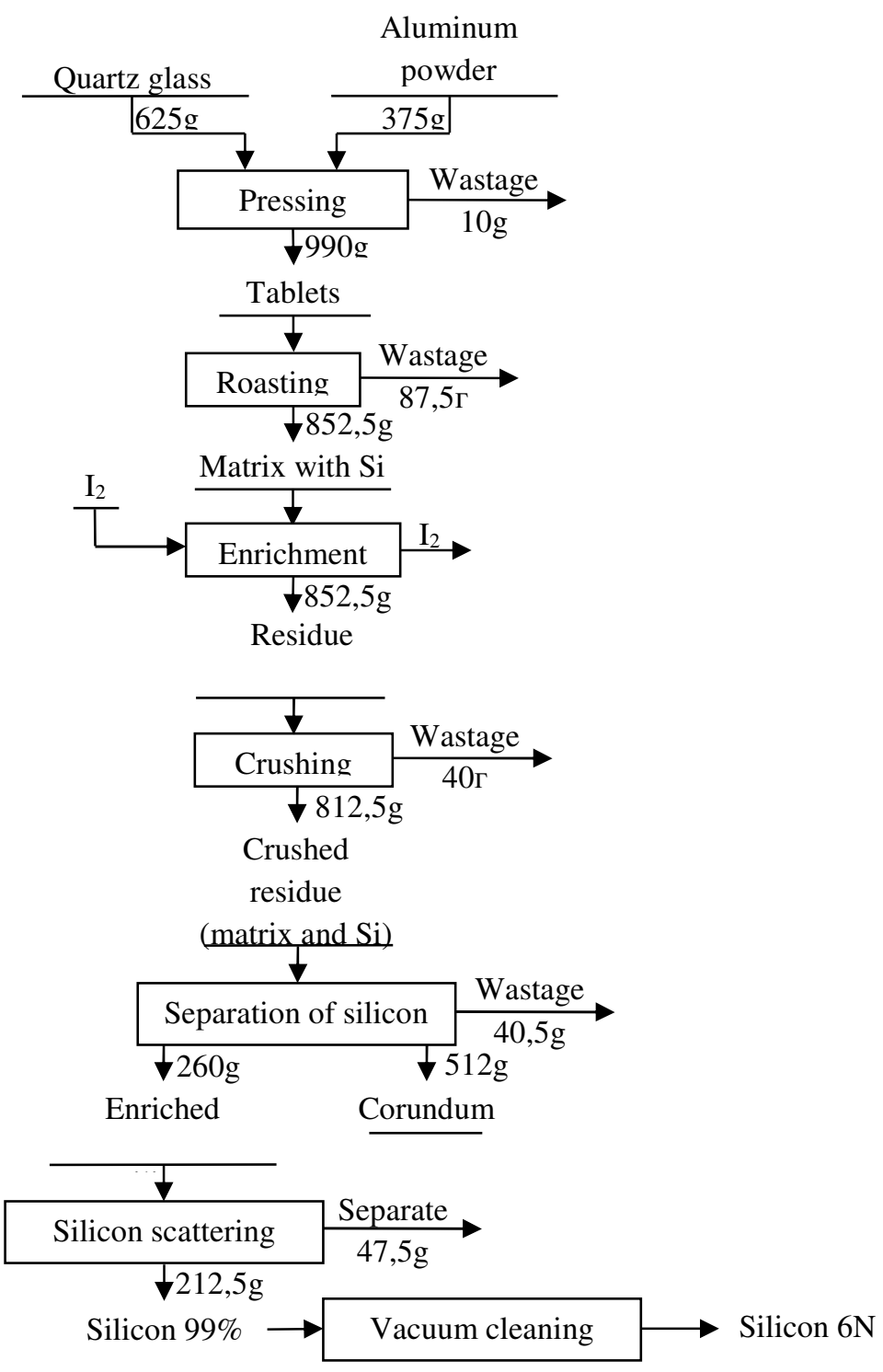

Fig.-8: Technological scheme of enlarged experiments.

\section{ACKNOWLEDGMENT}

This work was supported by the Ministry of Education and Science of the Republic of Kazakhstan for grant financing on the theme Development of aluminothermy method of silicon receiving of "solar" purity $(6 \mathrm{~N})$.

\section{REFERENCES}

1. A. Ciftja, T. Engh and M. Tangstad, Refining and Recycling of Silicon: A Review, Norwegian University of Science and Technology, Trondheim, p. 40 (2008). 
RASĀYAN $J$. Chem.

Vol. 11 | No. 3 |1050 - 1057 | July - September | 2018

2. M.G. Repetto and A. Boveris, Transition metals: Bioinorganic and redox reactions in biological systems, in: Transition metals: Uses and characteristics, Nova Science Publishers Inc., New York, pp. 349-370 (2012).

3. K. Yasuda, K. Saegusa and T. Okabe, Materials Transactions, 12(50), 2873(2009), DOI: 10.2320/matertrans.M2009260.

4. $\quad$ K. Yasuda and T.H. Okabe, JOM, 62, 94 (2010), DOI: 10.1007/s11837-010-0190-8.

5. M.S. Islam, M.A. Rhamdhani and G.A. Brooks, Solar-Grade Silicon: Current and Alternative Production Routesm, in: Chemeca 2011: Engineering a Better World, p. 448 (2011).

6. A.N. Romanova and Yu. A. Zykova, Application of Ground Silicon in Industry, in Youth Bulletin of Irkutsk State Technical University, Irkutsk State Technical University, Irkutsk (2012).

7. N.N. Lavrov, B.A. Lavrov and G.M. Serzhanov, Production of Polycrystalline Silicon by An Aluminothermic Method, Bulletin of Saint Petersburg State Institute of Technology (Technical University), 31(57), 30(2015).

8. V.M. Shevko, A.D. Badikova, B.A. Lavrov and Yu.P. Udalov, Stuttgart: European Applied Sciences, 3, 116(2017).

9. $\quad$ D.L. Perry, Handbook of inorganic compounds ( $2^{\text {nd }}$ edition), CRC Press, p. 581 (2011).

10. R.A. Lidin, Handbook of general and inorganic chemistry, Kolos, Moscow, p. 350 (2008).

11. E.L. Paul, V.A. Atiemo-Obeng and S.M. Kresta, Handbook of Industrial Mixing, Wiley Interscience, Hoboken, NJ (2004).

12. V.F. Ochkov, Mathcad 14 for students, engineers and designers, BHV-Petersburg, St. Petersburg, p. 368 (2007).

13. S.V. Digonskij, Carbothermic Reduction of Metals from Unoccupied Raw Materials, Chelyabinsk, p. 350 (2008).

14. V.M. Shevko, N.N. Lavrov, B.A. Lavrov and G.M. Serzhanov, Purification of Silicon by Iodine Transport, Bulletin of Saint Petersburg State Institute of Technology (Technical University), 36(62), 45-47 (2016).

15. G. Burns, J. Rabe and S. Yilmaz, Method of Removing Impurities from Metallurgical Grade Silicon to Produce Solar Grade Silicon, Patent United States \#20070202029A1 (2007).

16. S.M. Karabanov, V.L. Dzhkhunyan and V.I. Yasevich, Method for Purification of Metallurgical Silicon by An AC-Moistened Plasma in a Vacuum, Patent Russian Federation \#2465202 (2012).

17. S.M. Karabanov, V.L. Dzhkhunyan and V.I. Yasevich, Method of Refining Metallurgical Silicon by Dry Argon Plasma with Water Injection onto the Surface of the Melt Followed by Directed Crystallization, Patent Russian Federation \#2465199 (2012).

18. A.A. Kravcov, Method of Vacuum Purification of Silicon, Patent Russian Federation \#2381990 (2010).

19. Y. Norichika, Sh. Takehiko and M. Minoru, Method and apparatus for refining silicon using an electron beam, Patent United States \#20070077191A1 (2007).

[RJC-2038/2018] 